\title{
Recent Development in High-Content Reclaimed Asphalt Use
}

\author{
Jiang Chaoyang ${ }^{1}$ \\ ${ }^{1}$ Faculty of Geosciences and Environmental Engineering, Southwest Jiaotong University, Chengdu, Sichuan, China.
}

\begin{abstract}
In recent years, the use of recycled materials in construction and maintenance has increased significantly and been adopted as a common practice in the industrial field. Reclaimed asphalt pavement (RAP) is one of the most ideal materials that contain huge environmental and economic value. The present challenges faced with RAP is low utilization and degradation problems. Increasing the amount of RAP used in the mix design is considered an effective method to address these problems and can producing a three-fold benefit for the environment, economic, and landfill stress. The key point of increasing RAP use is usually reflected in the proper utilization of current production technologies, new mix design, and management. This paper summarizes the main limitation, distress, and present recent progress in high RAP use. The most common practice be utilized are the use of softer bitumen, softening additives and rejuvenators, while the application of warm mix asphalt technology also showed a positive result. The research results suggest that the utilization of those new practices could achieve better cracking resistance and improve the work-ability and rutting potential.
\end{abstract}

\section{Introduction}

Increasing the amount of RAP content in asphalt mixtures has a very high environmental and economic benefit. For the use of 50\% RAP in mixtures, the related cost savings can be achieved to $35 \%$. And the total recycled RAP can gain a more economic result of a $50-70 \%$ decrease in the related asphalt cost [1]. This shows a huge economic potential for future pavement construction. The environmental benefits of RAP use are generally reflected in the reduction of $\mathrm{CO} 2$ emission and the release of landfill stress. For the 100\% RAP asphalt, the emission of $\mathrm{CO} 2$ can be reduced for $18 \mathrm{~kg}$ per $\mathrm{t}$ [2]. The landfill stress of the disposal of RAP can also be addressed by increasing the use of RAP. Despite the vast environmental and economic benefit it brings to industrial companies, the currently available field performance test of 50\% RAP also showed a satisfied result under different weather conditions [3]. Recently, due to the significant rise in asphalt binder price, reduction of virgin materials, and increasing environmental awareness, increasing the RAP use of asphalt mixes has gained significant attention and become a hot topic of the research in this field. The objective of this paper is to summarize the main limitation and non-ideal performance of high-content reclaimed asphalt, and then present the recent progress in the research of increasing the content of RAP. This paper could give an insight to the future study of high-content reclaimed asphalt use.

\section{A brief view of current production and paving technology}

The super-heating technology are the most commonly used method to incorporate RAP into the asphalt. This method enables RAP to dry and heat and avoid direct exposure to the flame. The RAP content, moisture, and the required discharge temperature are three factors that will affect the super-heating temperature.

Plant equipment is the first requisites for the increase of RAP and is typically divided into the drum plant and batch plant. Drum plant is the most conventional one that can generally incorporate $50 \%$ RAP or the maximum $70 \%$ RAP into the asphalt mixtures [4]. The problems of maximum use of RAP is it will cause the volatilization of RAP binder and generate "blue smoke". Another plant is batch plants, which have a lower RAP use when compared with the drum plant. The average range of RAP can be incorporated into asphalt mixture is $10-20 \%$ and few result shows the RAP content surpasses $40 \%$ [4]. Some technologies designed for $100 \%$ RAP recycling by using these conventional techniques and equipment are also be introduced and available right now.

After the production of RAP is the paving procedure, this procedure is typically showed no difference with previous paving of asphalt [4]. However, the stiff aged binder contained in the high RAP mixture would have some effect on the engineering properties like the decrease of work-ability and compactability of the mixtures [5][6]. 


\section{Three main limitations for increasing RAP content}

There are typically three main limitations faced with the high RAP content mix design. The most direct one is the change of engineering properties that result in decreasing ductility and less elastic properties. The aging process of the asphalt can be divided into short term aging and long term aging and is generally depend on the aging time. Short term aging are generally happened in the mix process and due to the high temperature, while long term aging usually occurred in the later service stage [7]. The restoration of the aged binder is one of the most practical methods to address this problem and increase the RAP content in asphalt mixture
The second limitation faced with the high RAP mix design is the difficulty of control in the blending and diffusion process. To effective restore the engineering properties of the aged binder, the proper handle of blending and diffusion of the aged binder and new additives such as soft binder or rejuvenator is critically important. The key factor to ensure the successful blend between them are the RAP source and property and appropriately selected temperature and mixing time [5]. From current research studies, the degree of blending process between RAP and virgin binder can be generally divided into three levels: no blending, partial blending, and complete blending.

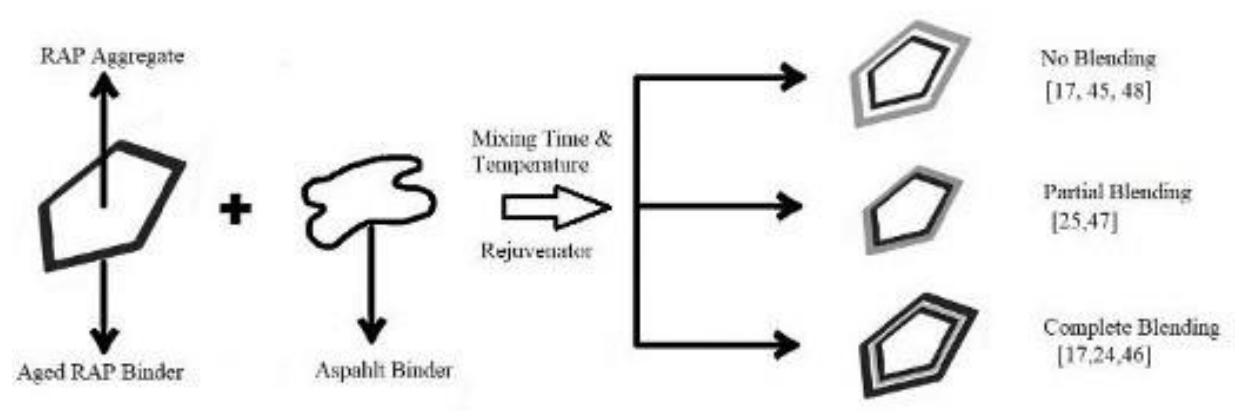

Figure. 1. Blending process[24]. .

The last limitation is about the RAP aggregate properties. The key point to ensure the same performance between the RAP asphalt pavement and conventional pavement is keeping the same RAP fraction with the virgin aggregate [8]. However, the current available RAP aggregate are generally fine aggregate due to the milling and crushing process, and can not meet the standard specified for virgin aggregates. Previous research are typically focused on the coarse RAP aggregates in cement concrete and very few research had been done to fine RAP aggregates. Therefore, the success of increasing the amount of RAP content in asphalt mixtures require the further research in the fine RAP aggregates.

\section{Unsatisfied performance of high RAP asphalt pavement}

The presence of aged binder and the use of recycling agent in the high RAP asphalt pavement could resulted in a different performance compared with the convention pavement. Those unsatisfied performance like potential cracking failure are the main reason impede the acceptance of government agencies and cause the low utilization of high RAP asphalt pavement [5][8].

Unsatisfied cracking and rutting performance are the main problem faced with high RAP asphalt pavement. The existence of aged binder are the main reasons for the poor performance of the high RAP asphalt pavement. The previous research of low RAP content asphalt pavement shown no obvious change in engineering properties compared with conventional asphalt pavement. But with the increase of RAP content in the mixture, the difference in the performance become increasingly obvious. For the asphalt mixture contain RAP content at the range between 40 to $55 \%$, an increase of 49 to $60 \%$ can be found in stiffness and result in a unsatisfied cracking performance and lower fracture energy[3]. However, the presence of aged binder could have a positive effect to the rutting performance. The rigid and in elastic properties of these aged binder can shown an excellent rutting resistance and has been confirmed in the $40 \%$ and $45 \%$ RAP mixture [5][9]. The recent research conducted by Jesse verified the feasibility of high RAP content using WMA and the result of the rutting performance is generally the same or better than the conventional mixtures [10]. The key point of achieving a desirable cracking and rutting performance are the proper use of recycling agent[3]. Both insufficient diffusion of recycling agent and over dosed use will result in a undesirable result and increase the substance of permanent deformation.

Water susceptibility is another concern for the high RAP asphalt pavement. The high RAP asphalt pavement generally has a better moisture susceptibility and less likely to contact with water, as the RAP aggregate had already be covered by asphalt [11]. The research result suggests that a better moisture susceptibility can be found in high recycled asphalt mixtures, and the same result had also be found in high RAP content using WMA [12].

The bleeding and flushing problems could also happened to high RAP asphalt pavement. The inappropriate use of recycling agents and rejuvenators can result in less friction of the pavement and are the main cause of this unsatisfied performance like flushing and bleeding [4][13]. 


\section{Current research in high-content reclaimed asphalt use}

The current research in high-content reclaimed asphalt are generally conducted in two different methods. The first kind of method are focused on the restoration of the aged binder properties and can be further divided into two different way. One is the utilization of softer virgin binder grade to offset the property change like increase stiffness resulting from the aging process, another one is the addition of recycling agents to improve the general engineering properties. The use of RAP to produce WMA mixes would also had a positive effect to restore and improve the engineering properties.

\subsection{Use of softer virgin binder grade}

The key point of the utilization of softer virgin binder grade is to ensure the appropriate amount of RAP and virgin binder to blend together, and the blending charts are the most common approach to realize it. The research conducted by West and Willis indicates that the use of softer virgin binder grade could achieve promising performance in cracking and raveling resistance and prolong the fatigue life [3][8]. For the more recent research, Tran's performance test of using softer bitumen in $20 \%$ and $45 \%$ RAP asphalt mixtures also referred to an excellent cracking, rutting, and roughness performance [12].

\subsection{Use of recycling agents}

The recycling additives blend with the aged binders are generally divided into softening agents and rejuvenators. The former is typically focused on reducing the viscosity of the aged binder, while the latter are used to restore the engineering properties of aged binders without compromise its service performance [13].

The current available rejuvenators in the market can improve the overall performance of the high RAP asphalt mixtures. The most important properties like cracking and rutting resistance, moisture susceptibility and indirect strength can all be effectively improved by proper use of rejuvenators [14].

The current research also showed the potential of using rejuvenating oils in increasing the RAP content in selected mixtures. For the short term aged reclaimed asphalt (RA) case study, the satisfying result can be found in the group of 30,60 , and $70 \%$ RA mixtures with no rejuvenators [15]. However, for the long term aged RA case study, the use of rejuvenators is necessary for the 30, 60 and 90\% RA to achieve a good performance [15]. Overall, the utilization of rejuvenating oils can successfully increase the RA content to the degree of $90 \%$ in the long term aging process [15].

In addition to the use of the most common conventional commercial rejuvenator products in the market, the feasibility of using some waste oils and waste plastic materials to achieve a similar restoration effects to the high RAP asphalt mixtures are also be considered and to be tested in a wide range. The most potential products are waste vegetable oil, waste engine oil, waste cooking oil, and Polyethylene Terephthalate (PET) derived additives.

Waste engine oil and waste vegetable oil were tested earlier and had gain a good result in the performance test. The research conducted by Silva to use waste engine oil to restore the aged binder suggest a significant improvement in penetration grade softening point. Waste engine oils can successfully improve the work-ability and fatigue life of the mixtures without compromising the performance of the moisture susceptibility and rutting resistance [16]. Bailey and Zoorob (2012) and Artamendi et al. (2011) confirmed the feasibility of using waste vegetable oils as rejuvenators and the result indicated a good result in reducing viscosity an stiffness and improving the properties of age binder [6]. There is no significant effect to the rheology property and general work-ability compared with conventional methods [6]. Waste cooking oils are generally incorporated into bio-asphalt binders and showed a positive effect to the chemical and rheological properties [17].

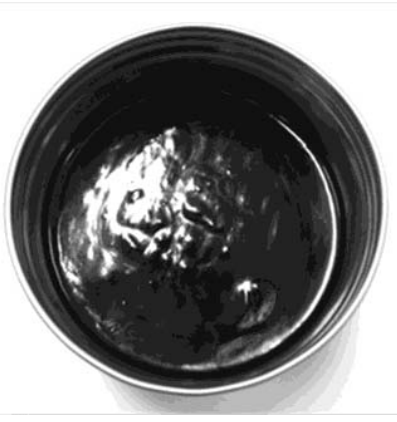

Figure 2. WCO based bio-oil residue[17].

The comparison test between the most common used recycling agents in the market and new organic recycling agent had been studied by Zaumanis. The general performance of waste engine oil, distilled tall oil, waste vegetable oil, and waste vegetable grease indicate that these novel alternatives to the conventional commercial rejuvenating products can achieve a good cracking resistance and effectively reduce the penetration of the aged binder [18]. However, the work-ability of asphalt mixtures using new organic recycling agent can not achieve a similar result as those using the convention recycling agents [18]. From the overall performance at the $12 \%$ dose degree in the test, waste vegetable oil are the most suitable and effective alternatives [18].

Waste plastic materials are another choice to achieve a similar restoration effect to aged binders. Polyethylene Terephthalate (PET) or their functionalized additives are the most potential materials to improve the age binder properties and can reduce the stress of the disposal of waste plastics. Form the result of recent research, the RAP mixture containing PET derived additives showed an improvement in rutting resistance, fatigue cracking resistance, and low-temperature properties [19]. 


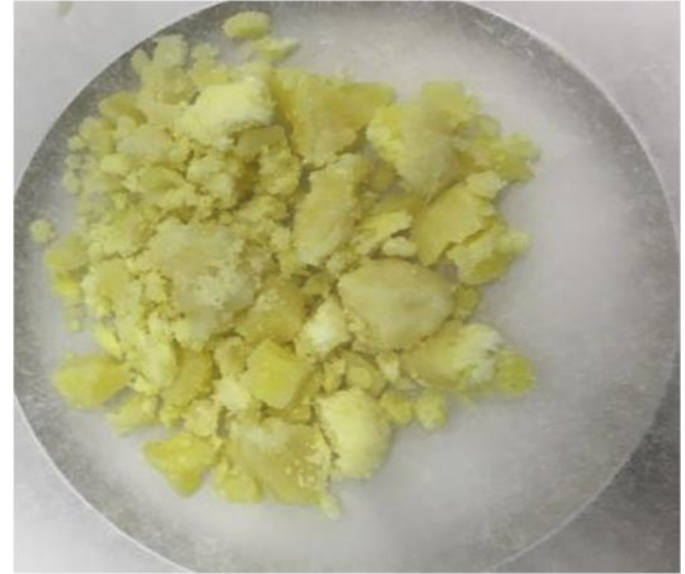

Figure 3. PET derived additive[19].

\subsection{Use of warm mix asphalt}

The advantage of WMA technology compared with HMA are the remarkable decrease of needed temperature. The lower temperature requirement will also result in less use of fuels and reducing the change of properties due aging process. Foaming technology, organic or wax technology are the most common method to WMA production.

The research suggested that the use of WMA could achieve a satisfied strength and durability performance [20].

For the 50\% RAP mixture using WMA foaming technology, the performance test of RAP mixture section showed an excellent result in cracking, rutting resistance, and texture property [9]. However, the rutting resistance of laboratory test is different from the field performance that had the highest rut depth, and the cracking resistance are worse than the conventional 50\% HMA mixtures[9].

From the recent research, it is found that with the mixture with 50\% RAP, WMA technology showed promising results in the rutting resistance and moisture susceptibility [21].

The use of warm-mix asphalt was also combined with some local material waste to achieve a higher environmental and economic effect in some research. Zeolite is the material that can be added to the powder mixing process of Asphalt Concrete Wearing Course type with the use of warm-mix asphalt. The ideal composition of this novel warm mix asphalt is $39.92 \%$ RAP, 56.40\% new aggregate, and 3.68\% new asphalt, with the $120^{\circ} \mathrm{C}$ mixing temperature[22]. The lower temperature requirement for WMA could dramatically reduce fuel consumption and $\mathrm{CO} 2$ emissions.

Similar research was also conducted with the addition of Retona asbuton (a native product in Indonesia) on asphalt concrete wearing course using the warm mix asphalt method. The research result indicates that the RAP content of $49.37 \%$ with $7 \%$ asphalt content and $4.13 \%$ new asphalt mixture could achieve better performance[23].

\section{Conclusion}

The increased interest in higher RAP use is continually rising in recent years, not only by the environmental benefits but also by huge economic effects. Recent research was generally dedicated to finding some innovative ways to solve the limitation and distress in a high RAP mix design and increase the RAP use. The research results suggest that the proper use of recycling agents like softer binder, softening additives, and rejuvenators could improve the chemical and physical performance of the aged binders and increase the amount RAP content, and the use of WMA technology showed huge benefits in reducing the fuel consumption and $\mathrm{CO} 2$ emissions while not compromising the restoration of the properties of aged binder. Through these new methods of in high-content reclaimed asphalt, the cracking, rutting, fatigue failure, and work-ability performance all showed a good result in the test. For the future research of high-content reclaimed asphalt, some other consideration should also be considered: proper milling practice, appropriate management of RAP, and availability of RAP processing equipment. The future research may more focused on the full-scale demonstration project and conduct more field tests to the high-content reclaimed asphalt.

\section{Acknowledgement}

I would like to thank Prof. Buyukozturk and Yvonne for their help to my paper.

\section{References}

1. J.D. Brock, J.L. Richmond. Milling and recycling. Chattanooga, TN: ASTEC, Technical Paper T-127, (2007).

2. M. Zaumanis, R.B. Mallick, R. Frank. 100\% recycled hot mix asphalt: A review and analysis.Resources, Conservation and Recycling, 92:230-245, (2014)..

3. R. West, J.R. Willis, M. Marasteanu. Improved mix design, evaluation, and materials management practices for hot mix asphalt with high reclaimed asphalt pavement content. Auburn, AL: National Center for Asphalt Technology, Report Number NCHRP. 752, Project Number 09-46, (2013).

4. P.M. Kandhal, and R.B. Mallick. Pavement recycling guidelines for state and local governments-participant's reference book. Auburn, AL: National Center for Asphalt Technology, Report Number FHWA-SA-98-042, (1997).

5. W.S. Mogawer, et al. Performance characteristics of plant produced high RAP mixtures. Road Materials and Pavement Design, 13(1):183-208, (2012). doi:10.1080/14680629.2012. 657070.

6. I. Artamendi, et al. Rejuvenation of bituminous mixtures containing reclaimed asphalt with used vegetable oil. In: 5th international conference bituminous mixtures and pavements, 1-3 June 2011 
Thessaloniki, Greece. Thessaloniki: Aristotle University of Thessaloniki, 1024-1033, (2011).

7. I.L. Al-Qadi, M.A. Elseififi and S.H. Carpenter. Reclaimed asphalt pavement: a literature review. Spring- field: Illinois Center for Transportation, Report Number FHWA-ICT-07-001, (2007).

8. J.R. Willis, et al. Effects of changing virgin binder grade and content on RAP mixture properties. Auburn, AL: National Center for Asphalt Technology, Report Number NCAT 12-03, (2012).

9. R. West, et al. Phase IV NCAT pavement test track findings. Auburn, AL: National Center for Asphalt Technology, Report Number NCAT 12-10, (2012).

10. J.D. Doyle, I.L. Howard. Rutting and moisture damage resistance of high reclaimed asphalt pavement warm mixed asphalt: loaded wheel tracking vs. conventional methods.Road Materials and Pavement Design, 14(Supp 2), 148-172, (2013).

11. N.H. Tran, A. Taylor, R. Willis. Effect of rejuvenator on performance properties of HMA mixtures with high RAP and RAS contents. Auburn, AL: National Center for Asphalt Technology, (2012).

12. N. Tran, R. West, A. Taylor, R. Willis. Evaluation of moderate and high RAP mixtures at laboratory and pavement scales.International Journal of Pavement Engineering, 18(9):851-858, (2017).

13. R. Karlsson and U. Isacsson. Material-related aspects of asphalt recycling-state-of-the-art. Journal of Materials in Civil Engineering, 18(1):81-92, (2006). doi:10.1061/(ASCE)0899- 1561(2006)18:1(81)

14. I. Rodríguez-Fernández, P. Lastra-González, I. Indacoechea-Vega, D. Castro-Fresno. Recyclability potential of asphalt mixes containing reclaimed asphalt pavement and industrial by-products. Construction and Building Materials, 195:148-155, (2019).

15. D. Lo Presti, A.J.d.B. Carrión, G. Airey, E. Hajj. Towards $100 \%$ recycling of reclaimed asphalt in road surface courses: binder design methodology and case studies. Journal of cleaner production, 131:43-51, (2016).

16. H.M.R.D. Silva, J.R.M Oliveira, C.M.G. Jesus. Are totally recycled hot mix asphalt a sustainable alternative for road paving? Resources Conservation and Recycling, 60, 38 - 48. doi:10.1016/j.resconrec. 2011.11.013, (2012).

17. C. Wang, L. Xue, W. Xie, Z. You, X. Yang. Laboratory investigation on chemical and rheological properties of bio-asphalt binders incorporating waste cooking oil. Construction and Building Materials, 167:348-358, (2018).

18. M. Zaumanis. $100 \%$ recycled hot mix asphalt and the use of rejuvenators. Thesis (PhD). Worcester Polytechnic Institute, (2014).

19. Z. Leng, A. Sreeram, R.K. Padhan, Z. Tan. Value-added application of waste PET based additives in bituminous mixtures containing high percentage of reclaimed asphalt pavement
(RAP).Journal of cleaner production, 196:615-625, (2018).

20. B. Prowell, G. Hurley. Warm-mix asphalt: best practices. Quality Improvement Publication 125, 3rd edn. NAPA, Lanham, MD, (2008).

21. W. Song, B. Huang, X. Shu. Influence of warm-mix asphalt technology and rejuvenator on performance of asphalt mixtures containing 50\% reclaimed asphalt pavement.Journal of cleaner production, 192:191-198, (2018).

22. M. Winas, R. Susanto, S. Jachrizal, S. Sumabrata, H. Pranowo, R. Hadiwardoyo, A. Suyuti. Influence of amount of reclaimed asphalt pavement and asphalt using warm mix asphalt method on asphalt concrete wearing course. AIP Conference Proceedings, 2019, 2114(1).

23. R.A. Suyuti, R.J. Sumabrata, S.P. Hadiwardoyo, D. Iskandar. The use of reclaimed asphalt pavement by adding retona asbuton on asphalt concrete wearing course using the warm mix asphalt method. AIP Conference Proceedings, 2114(1), (2019).

24. L. Devulapalli, K. Saravanan, G. Sarang. A review on the mechanisms involved in reclaimed asphalt pavement.International Journal of Pavement Research and Technology, 2019, 12(2), 185-196. 